\title{
Chronic Infective Metritis.*
}

\author{
By Augustus W. Addinseld, M.B., M.R.C.P., \\ Physician to the London Temperance Hospital.
}

There occur from time to time cases in which intermenstrual bleeding, at first slight in amount, but gradually increasing, calls the attention of the patient to the fact that all is not right. Enquiry elicits the statement that the periods are increasing both in frequency and in amount. They last longer and are more severe, and there are often intermenstrual hæmorrhages. In severe cases the bleeding may be almost persistent with the intervals of freedom shorter than the periods of bleeding. Examination reveals nothing abnormal. The ovaries and Fallopian tubes are felt to be free from any gross lesion. The uterus is perfectly mobile, perhaps slightly enlarged, but not markedly so. If the sound be passed its canal does not measure more than 3 or $3 \frac{1}{2}$ inches in length.

The verdict may be, and generally is, that the patient is suffering from sub-involution. Various suggestions of treatment are offered. Hydrastis, hamamelis, ergot and all the usual drugs are tried without benefit. Finally curettage is resorted to. There may be temporary relief, but not always. Sometimes the bleeding is increased. Why is this? No fibromyomata can be detected, and, with the exception of the hæmorrhage, there is no reason to suspect malignant disease. Why then should these patients bleed?

It not unfrequently happens that the hæmorrhage from one of these uteri is so severe, so persistent, and uncontrollable that hysterectomy has to be resorted to. When the removed organ is examined, to the naked eye it appears normal, but a very striking condition is immediately observed under microscopical examination.

The following case will best illustrate the condition :-

M.S., aged 33, married 13 years, had one child 12 years ago. She menstruated at 14; was always regular; had no pain, and the loss was moderate in amount up to the time of her marriage. The confinement was followed by a long illness of three months, which was caused by what she describes as " chill" at the time accompanied by "high fever" and "internal inflammation."

- Read before the Obstetrical Society of London, April 4th, 1906. 


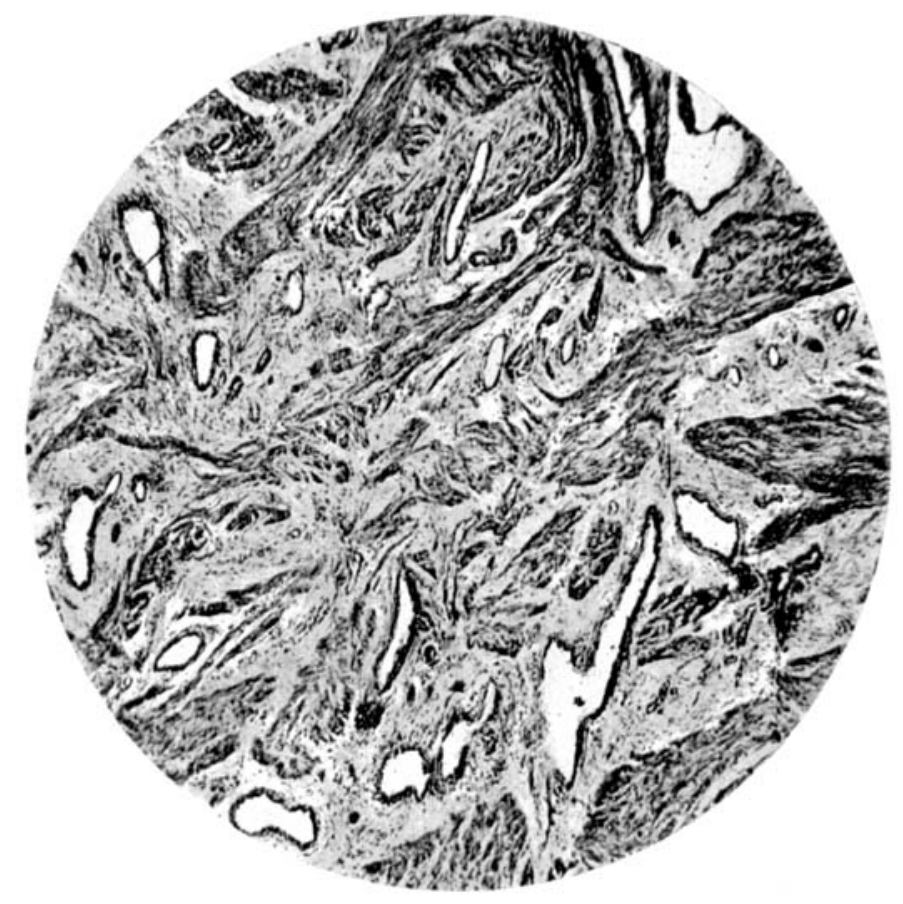

FIG. I.

Great increase of fibrous tissue almost entirely replacing muscle tissue; increased vascularity, but no thickening of arterial walls. Some of these spaces are probably dilated lymphatics. Low power. 


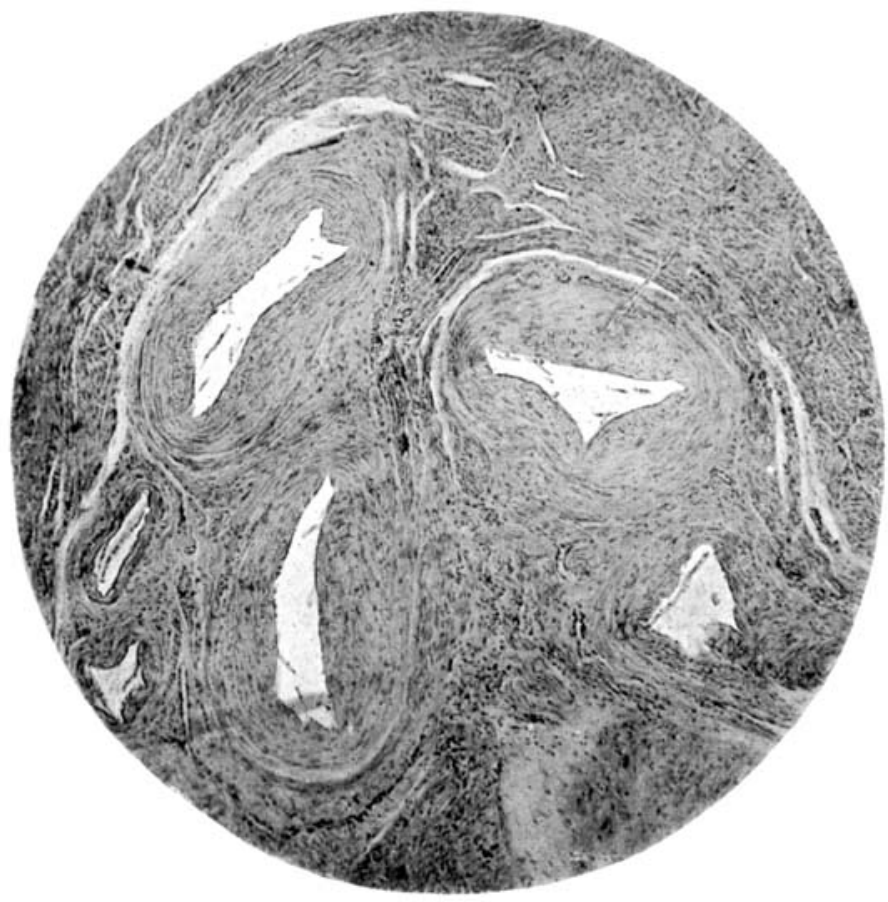

Fig. II.

Group of vessels, showing thickened middle coat and distortion of lumen, together with a patch of commencing hyaline degeneration. 
Since the birth of the child twelve years ago there has been an increasing tendency to a shortening of the intermenstrual intervals28 days to 25 , then to 23. This was very gradual, but for the last $3 \frac{1}{2}$ years she rarely went more than 17 days at the longest without a return of hæmorrhage. Three years ago there commenced slight intermenstrual coloured discharges. She was then curetted by a Continental physician. This was followed by severe and prolonged hæmorrhage, necessitating her confinement to bed for a month. After that the periods were more profuse and more frequent, until the early part of 1904, when she was again curetted by a doctor, in this country. This second curettage was again followed by hæmorrhage and a six weeks' illness.

Late in the year 1904 she came under the care of Dr. Hamilton Bland, who placed her in a Nursing Home, and satisfied himself of the severity of the hæmorrhages and the length of time they lasted. There was continuous bleeding, varying in amount, but often severe, from January 12th, 1905, to March 5th. I was then asked to see her in consultation with Dr. Bland.

The patient was profoundly anæmic. The lips and mucous membranes were colourless. She was wretchedly weak, and looked very ill; unable to take any exercise or interest in her surroundings, and confined either to bed or the sofa.

Examination revealed nothing abnormal in the pelvis. The sound was not passed, but the uterus did not feel enlarged. All the usual remedies of ergot, hamamelis, hydrastis, douches, and curettage had been tried without effect. The Sister of the home assured me of the alarming quantity of the hæmorrhage. I advised hysterectomy.

On March 8th I removed the uterus by the abdominal route, leaving both ovaries. Convalescence was without incident. A year has now passed. The benefit to the patient's health is most gratifying. She is now a perfectly strong and happy woman, and able to fulfil all her duties.

The walls of the uterus, after its removal, were felt to be rather denser than normal. It measured less than three inches in length.

Microscopical examination reveals the following changes:Under the low power attention is immediately directed to the marked peri-vascular and peri-glandular proliferation of small round cells. These cells can be traced along the lines of vessels, and in many places show a tendency to invade the muscle wall, making their way into the inter-muscular connective-tissue. In some fields there are groups or masses of round cells occupying quite a considerable area. Wherever the glands of the endothelial lining membrane dip more 
deeply into the musculature there are to be seen surrounding these invading glands many small round cells. The higher power shows the tendency to separation of the bundles of muscle fibres by small cells, and the odematous condition of the muscle walls is well marked. There are many dilated lymphatics scattered throughout the whole area of the musculature, and evidence of inflammation surrounding these dilated lymphatics and newly-formed blood-vessels is everywhere abundant in the groups of round cells surrounding these structures.

Having regard to the age of this patient, the arteries are distinctly thickened, and in some fields there is a considerable increase in the number of quite small vessels. This thickening is chiefly in the middle coat, but the outer coat is also involved. Many vessels are distorted in shape, and some almost obliterated, but the most striking feature is the increased vascularity, that is, the greatly augmented number of small vessels distributed through the muscle wall.

The endometrium is scanty in amount, though normal in appearance, save in that part which is immediately adjacent to the muscle wall. Small groups of round cells may be seen, and can be traced up along the line of invading vessels and glands into the musculature. With this solitary, though important, exception the endometrium is normal.

In searching for literature that would throw any light upon this condition I find there are recorded isolated cases or small groups of cases by various authors under various titles.

In the June number of the Journal of Obstetrics and Gynacology of the British Empire, 1905, there appears an article by Dr. Freeland Barbour, of Edinburgh, entitled "Climacteric Hæmorrhage." $\mathrm{He}$ there cites an interesting case of his own, where there was marked sclerosis of the uterine vessels, and to such a degree that the vessels stood out on section of the organ.

Mr. Bland-Sutton, in the Lancet of May 27th, 1905, refers to some cases under the title of "Uterine Fibrosis." The chief symptom was persistent and severe hæmorrhage which necessitated hysterectomy. Again, as far back as 1899, he says, in the British Medical Journal for that year: "I take the view that these fibrotic changes are secondary to chronic infective metritis, and are analogous to that curious fibroid change (syphilitic) which occurs in the muscle tissue of the heart, and which entails consequences so serious as sudden death."

Dr. Palmer Findley, in the American Journal of Obstetrics, Vol. xliii., 1901, describes some cases under the title of "Arteriosclerosis." His attention seems to have been confined entirely to 


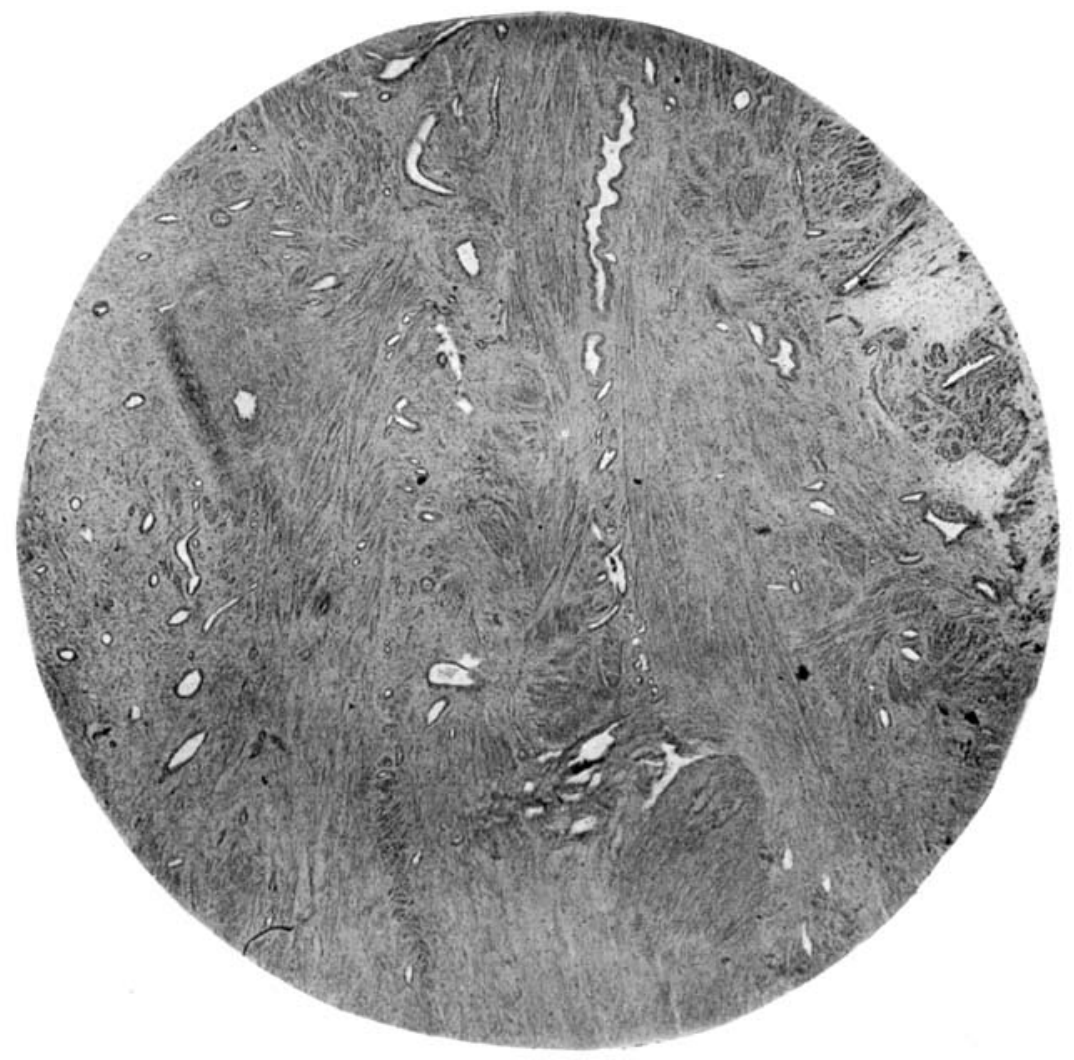

Fig. III.

Very extensive degeneration of uterine wall; only faint traces of muscle fibre are to be found; enormous increase of small vessels and dilated lymphatics. 'This change resembles hyaline degeneration under the low power. 


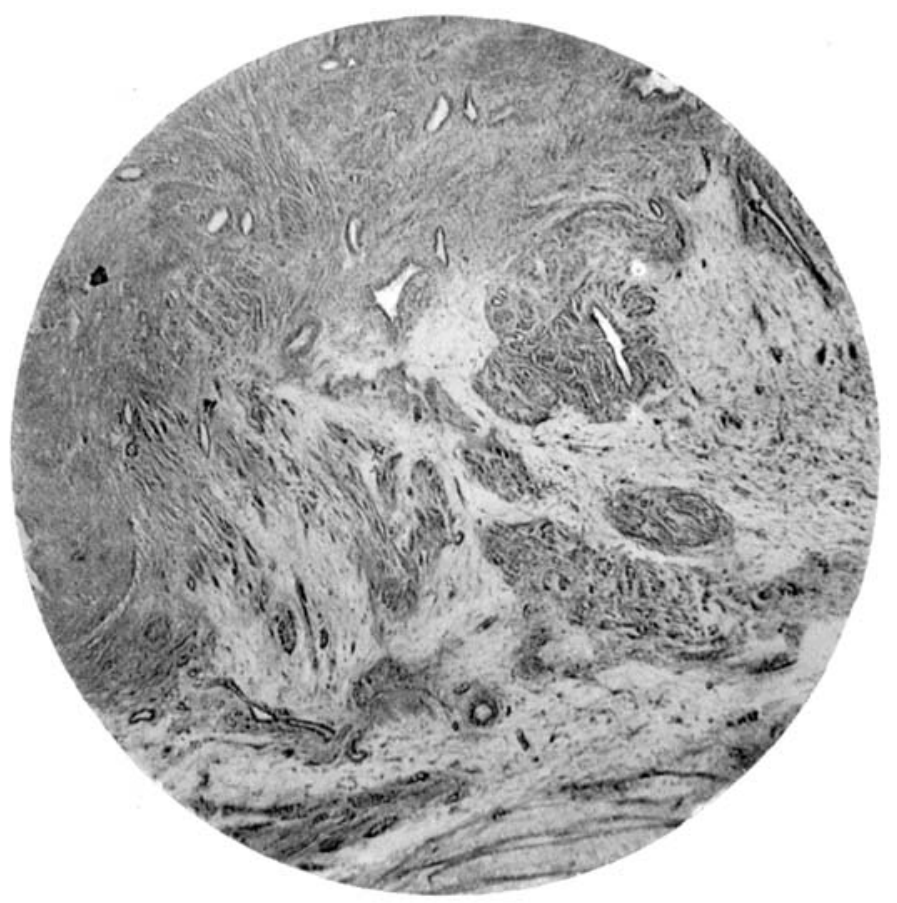

Fig. IV.

There has been great increase of intermuscular fibrous tissue, which has undergone degeneration, closely resembling hyaline degeneration in appearance. Some of the arteries are greatly thickened, and these have also undergone degeneration. 
the arterial changes, though he incidentally refers to the changes in the muscle wall, saying briefly: "There was atrophy and degeneration of the musculature." Now in all cases that were quoted by Dr. Palmer Findley the patients' ages are given from 40 to 49 . Dr. Barbour's patient with climacteric hæmorrhage was aged 46.

Gottschalk, in the Archiv für Gynäkologie, Vol. lxvi., 1902, quotes two cases of arterio-sclerosis, but the ages were 61 and 56 .

It is clear therefore, from the ages given by the various authors I have quoted, that their patients were at or about the menopause. Now all my cases may be fairly described as young women. The youngest was 29 , and the eldest 34 . The importance of this is easily seen, for as age advances in multiparous women and the menopause draws near, it is found to be the normal condition for the arterial walls to be thickened. The age of the patients under discussion has therefore an important bearing upon the histological changes. Moreover none of my patients was multiparous.

At the meeting of the London Obstetrical Society in October, 1905, I showed a uterus (with microscopical sections) which had been removed for tubercular disease. The woman had suffered from continuous hæmorrhage, varying in amount from a mere staining to occasional flooding, but incessant. The microscope showed tubercle from cervix to fundus in the endometrium, but in addition to this there was evidence of inflammation affecting the whole uterine wall, viz., much increase of fibrous tissue and marked peri-vascular proliferation of small round cells. In many places fibro-blasts were in the process of formation. This particular case is interesting, as it was originally the seat of tubercular disease, but as this patient suffered from complete prolapse, the uterus being actually outside the vulva, it had become eventually the seat of a mixed infection, as the cervix was markedly eroded and covered with foul septic discharge. It is interesting to notice the distribution of the tubercle. This was entirely confined to the endometrium, whereas the chronic inflammation of the uterine wall had affected it through the whole of its structure. The most advanced changes were to be seen in that portion of the wall lying immediately under the peritoneum, whilst it is evident from the changes to be seen in that portion of the muscle wall lying nearest the endometrium that this structure has been the portal through which infection of the uterine wall entered.

Dr. Freeland Barbour quotes Richelot, who draws a distinction between arterio-sclerosis and true inflammation, for he says: "The former depends on vascular changes, the latter on infection." 
That infection plays a very important part in the condition now being discussed seems clear from the following case :-

Mrs. F., aged 31, married eleven years, had never been pregnant. In March, 1901, the period did not appear. Hitherto she had been regular every 28 days, and suffered no pain. It usually lasted four to five days. At the end of April she met with an accident. There was violent hæmorrhage, which reached alarming proportions. She was curetted in the country. This was followed by a severe and protracted illness, keeping her in bed for three months.

In January, 1902, I saw her for the first time. She told me that since her illness she had been bleeding seven or eight, sometimes ten or twelve days at each period, and for the last six months there had been an intermenstrual discharge, which was gradually increasing in severity, and that it had been continuous for the last ten weeks. This was confirmed by her husband and her maid. She was kept in bed for the next fortnight in order that I might assure myself as to the severity of the hæmorrhage. The anæmia from this continuous loss was profound. Abdominal hysterectomy was performed. Examination of the uterus revealed a condition similar to that described in the first case.

This case is peculiarly complete in that we have the cause originating in septic inflammation following curettage for what was probably an early miscarriage. Here, the infection starting at the endometrium has invaded the whole of the uterine muscle wall. This patient is now completely restored to health.

My attention was first directed to this condition of chronic infective metritis by a very striking case, a brief recital of which may be of interest:-

N.L.T., aged 31 , was married at 20 , and had one child 18 months after marriage.

She first consulted me in 1897, and told the following story :She had never been well since the birth of her child, which was then 8 years old. She had suffered from severe leucorrhoea; her periods had increased both in quantity and in the length of time they had lasted, and she was unable to stand long, or walk far on account of a continual bearing-down pain "as if her insides were coming out." For the last two years she had noticed that her discharge, which was formerly yellow, was nearly always tinged with blood.

She was painfully emaciated. A very tall woman, standing $5 \mathrm{ft} .11 \frac{1}{2}$ in., she weighed but little over 7 stone. She was profoundly anæmic, and spent most of her time either in bed or on the sofa. She was unable even at the best of times to walk half a mile. 


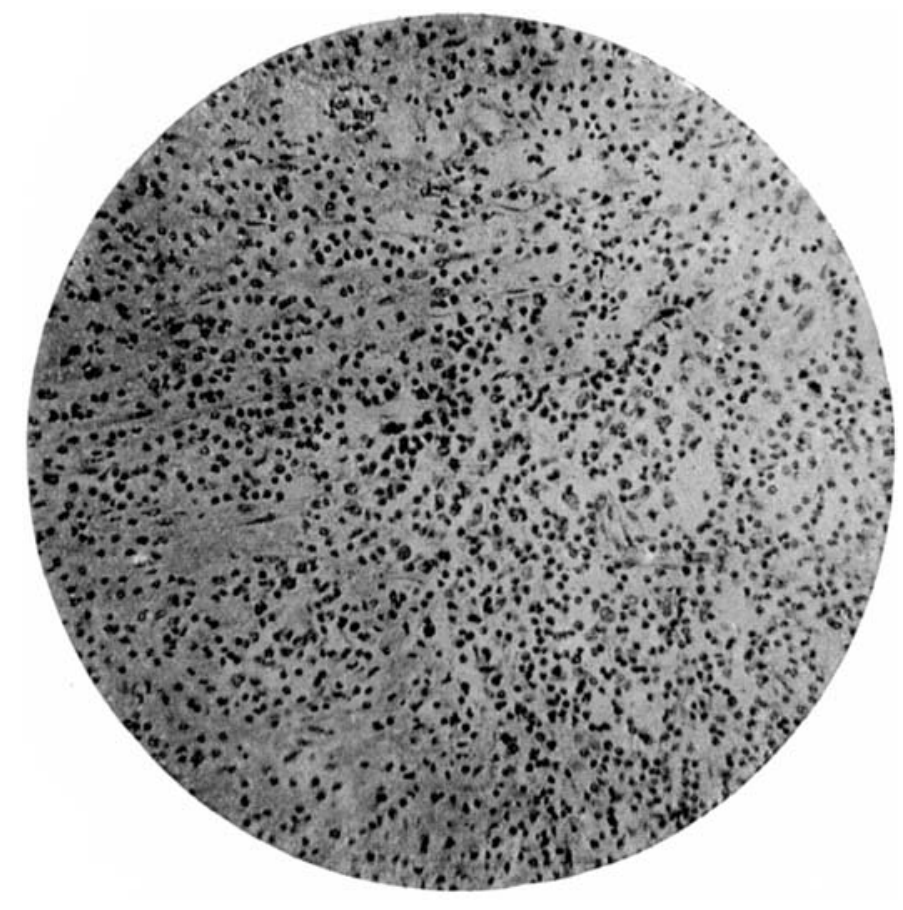

FIG. V.

Group of round cells invading muscle wall from endometrium. Muscle fibres can be seen in the upper part of the field, where the round cells are less numerous. IIigh power. 


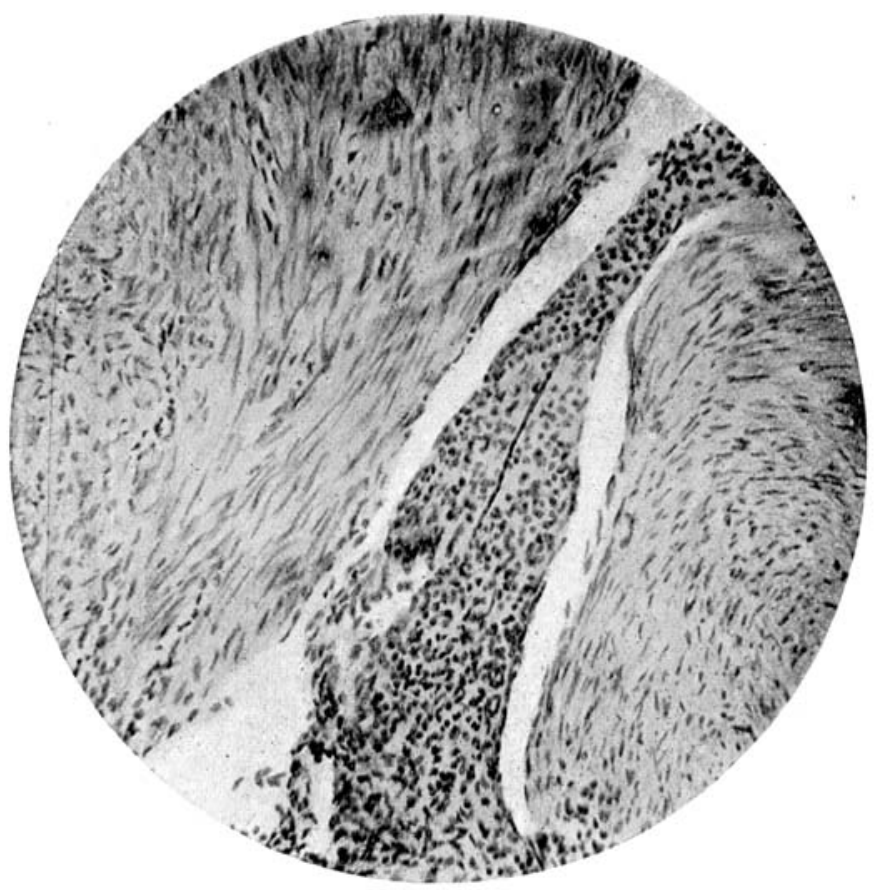

Fig. VI.

Mass of round cells surrounding a vessel and invading the muscle wall. High power. 
She had passed through the hands of several of the most distinguished gynæcologists of the day. She had been curetted three times and had had two rest cures of six weeks each, and all of noavail.

Examination showed perineal laceration almost to the rectum, a transverse laceration of the cervix up to the vaginal roof. There was an extensive scar in the vaginal roof on the left, and a less extensive one on the right. The uterus was considerably prolapsed. The cervical lips were completely everted, greatly thickened, and bathed with a copious discharge.

In consultation with the late Dr. William Playfair, it was decided to perform a trachelorrhaphy with colporrhaphy and a perineorrhaphy. This was accordingly done. At the same time she was again curetted. For some six months there was a distinct improvement. At the end of twelve months the intermenstrual hæmorrhages increased in severity, and the patient's general health was distinctly worse.

At this time Mr. Bland-Sutton saw the case with me. He advised hysterectomy, advice with which, however, I did not agree, and so the patient remained in this unsatisfactory condition, drifting from bad to worse for another six months, when it became evident that delay was no longer justifiable. I therefore performed vaginal hysterectomy, and the patient is now perfectly well and restored to health.

I have only one regret in connection with this case, and that is, that I did not accept the advice of Mr. Bland-Sutton when he first proffered it.

The following are the pathological notes of the case, and photographs have been made of the sections which well illustrate the fibrotic changes which have occurred:-The uterus was removed by vaginal hysterectomy. There was a transverse laceration of the cervix extending to the vaginal roof; both anterior and posterior lips were everted, greatly thickened and denuded of mucous membrane. The walls felt denser and firmer than normal. There were no obvious cbanges in the endometrium, but a very striking alteration of the muscle wall was immediately noticed when examined under the microscope. The muscle tissue was split into islands, with broad bands of fibrous tissue running in all directions. In places, this fibrous overgrowth was dense and well organized, whilst in other places it was undergoing degeneration, taking the stain badly, and looking like a homogeneous surface studded with small perforations. Many of these are probably dilated lymphatics, whilst others are small blood-vessels, for corpuscles may be seen in situ. In other fields, again, the process of inflammation is evidently more recent, for masses of round cells may be seen surrounding and accompanying 
blood-vessels, and separating the muscle fibres, and evidently invading the territory of the musculature. Indeed there are observed fibroblasts in process of formation into organized fibrous tissue.

So far the cases recorded illustrate two distinct stages of inflammation.

It will be remembered, in recording the histological changes of the first case, the chief and dominant feature was peri-vascular and peri-glandular proliferation of round cells, entering the muscle wall through the endometrium, tracking along the vessels, and gradually invading the muscle wall itself.

In the case just recorded the most noticeable feature is the extraordinary overgrowth of fibrous tissue which has separated the bundles of muscle fibres and replaced the muscle tissue.

In the next case the histological changes are those which I conceive to be the final stage of chronic infective metritis.

This patient was aged 31 at the time she consulted me in 1901. She had one child, aged 9. There was a history of a miscarriage four years previously to my first seeing her. About this time, that is, in 1897, she had suffered from an acute copious yellow discharge and painful micturition; was acutely ill for some weeks, giving in fact the history of an acute attack of gonorrhoea. From the time of this miscarriage she dates her illness. The hæmorrhages, which up to that time had lasted five or six days, and were of the 28 days' type, had increased to an alarming extent. Intermenstrual hæmorrhages had been frequent and severe. The woman was evidently very ill. On one occasion the hæmorrhage came on with such severity and alarming rapidity that she had to be lifted from her horse and laid on the ground in the hunting field.

I saw her in London in the early part of 1901. She lay in bed for six weeks with continuous hæmorrhage, being never entirely free; sometimes it was slight, but oftener very severe. She had been curetted six months before. The doctor in the country, who came up to town, assured me of the alarming extent of her hæmorrhages. All the usual remedies, viz., ergot, rest, hydrastis and hot douches were tried. At the end of six weeks the bleeding became markedly less. She was then sent to Woodhall Spa to recover, but in June she was again brought up to town by her husband and her medical attendant, as she had suffered from another severe attack of hæmorrhage.

Dr. William Playfair saw her with me at this time, in consultation, and advised hysterectomy. Dr. Hugh Playfair assisted me at the operation. The recovery was without incident, and she is now restored to perfect health. 
The following are the notes of the histological changes of the uterus:-It measured three inches in length. There was nothing noticeable in the endometrium, but the changes in the uterine wall are the most remarkable that $I$ have ever seen, and I have examined a very large number of uteri. There is under the low power very extensive degeneration of the whole of the uterine wall. Scarcely any muscle fibre is to be detected at all; only faint traces here and there are to be found. There is an enormous increase of small vessels and dilated lymphatics. In whatever part of the section one looks it is literally studded with small spaces. The arterial walls are greatly thickened, and this thickening, as is almost universally the case in all instances that $I$ have examined, is chiefly in the middle coat, and under the high power this middle coat is itself undergoing degenerative changes. In some parts of the field, an exaggeration of the condition described in the last case may be seen. Here and there may be seen the remains of muscle tissue arranged in small patches. There has evidently been an immense overgrowth of intermuscular connective-tissue which has undergone degeneration. This degeneration closely resembles in appearance hyaline degeneration. In the photographs which have been taken both under the higher and lower power, the changes that $I$ have described are very well shown.

The hæmorrhage from this patient was, with one exception, the most severe that I have ever seen, and that exception took place in a patient of Dr. Eden's, a good many years ago, when I was at the Chelsea Hospital for Women as Pathologist, in which changes were found very similar to those $I$ have described.

From a study of the clinical history together with the pathological changes of these cases, of which I have selected the most striking as illustrations, $I$ have arrived at the conclusion that chronic infective metritis may be responsible for the hæmorrhage occurring from uteri in which no malignant disease can be found and which are not the seat of fibro-myomata. In all the cases that I have studied there has been a history of infection of some sort or another. I have searched diligently and spent many hours in the endeavour to discover some micro-organism, but hitherto I have not satisfied myself sufficiently to be able to demonstrate it, although in some of the slides from the first case described, which stained especially for micro-organisms with gram, I found something very suspiciously like streptococcus.

There can be little doubt as to the cause of infection in the last patient. She was evidently the victim of a gonococcal infection, which must have been extremely acute to have wrought such devastation in her uterus as was demonstrated by the microscope. 
In the earlier part of this paper I referred to the age of the patient as an important factor. It is clear that these cases stand in a category altogether outside the hæmorrhages of the climacteric period of Dr. Freeland Barbour's case or of the arterio-sclerosis group of Dr. Palmer Findley, or of Gottschalk, whose patients were 56 and 60 . Indeed if the reading of these cases be true, age has nothing to do with the condition.

I do not suggest that I am describing a new disease. All I claim is that these cases, instances of which have probably occurred to all or most of us, deserve to be placed in a class of their own, and I have suggested the title "Chronic infective metritis," because it appears to be the most inclusive term, and consistent with general pathology. It is true that Mr. Bland-Sutton's cases of fibrosis come into this category, but the term "fibrosis" would exclude the first of my cases and the last of them, whereas I cannot help thinking that his is only one stage, and that the middle stage of a process of inflammation of the uterine wall, of which round-celled infiltration is the first, intermuseular fibrosis is the second, and degeneration of this fibrous overgrowth is the third or final stage. That these three stages gradually merge the one into the other, and that two of them may, and do, exist in the same uterus is evident from a close study of the histology of these cases, for in my first case there is evidence in a larger grouping of round cells that fibro-blasts, which eventually develop into fibrous tissue, are in the process of doing so, and in the second case, where the fibrous tissue is the most prominent feature, there are fields illustrating the maturity of the first stage and the infancy of the third, but the case which affords the best opportunity for studying the whole process of inflammation is provided by the section of the tubercular uterus which $I$ showed at the October meeting. There the infection was probably primarily tubercular. I say probably because it was most in evidence in the endometrium, and the history of tubercle was absolutely complete in other organs of the body, but this is by no means certain, for the patient was the subject of complete procidentia. The uterus was outside the vulva. It was exposed to a mixed infection, and might easily become the seat of tuberculosis superimposed upon an already diseased organ, but in any event whether the tuberculosis was primary or secondary, the histological appearances are those of "chronic infective metritis."

With regard to treatment, it is clear that after all palliative measures have been tried and persevered with, hysterectomy is the only course that is open to us.

Drugs and curettage, local treatment by douches, tampons of 
glycerine and icthyol, and various intra-uterine medicaments should all be given a fair chance, but if the hæmorrhage is severe, persistent and uncontrollable, then I think one should not hesitate to advise and perform hysterectomy, for I take it that the responsibility of declining to perform an operation of the necessity for which one has convinced oneself, is at least as great as the responsibility of performing an operation of the necessity for which one is in doubt. 